\title{
HPTLC Fingerprinting: A Tool for Simplified Analysis of Phenolics in Medicinal Plants
}

\author{
Amit Yadaorao Saraf ${ }^{1, *}$, Aparna Amit Saraf ${ }^{2}$ \\ ${ }^{1}$ Department of Botany, Government of Maharashtra's Ismail Yusuf College, Jogeshwari (E), Mumbai, Maharashtra INDIA. \\ ${ }^{2}$ Department of Botany, Dr Homi Bhabha State University, The Institute of Science 15 Madame, Mumbai, Maharashtra INDIA.
}

\begin{abstract}
Background: Phenolic compounds especially the flavonoids and tannins comprise one of the most significant classes of plant secondary metabolites. Aim: HPTLC is widely accepted by WHO and pharmacopoeia across the globe as an effective analytical method for the investigation of phenolics in herbal analyses. Materials and Methods: The methanolic extracts of Abrus precatorius L., Sapindus trifoliatus L. and Embelia ribes Burm. F. were developed on the HPTLC system to study the diversity of phenolic compounds like flavonoids and tannins under different development conditions. Flavanoids were separated using the combination of solvent system comprising of mid-polar to polar solvents, hence Ethyl acetate: formic acid: glacial acetic acid: water (10:0.5:0.5:1 $\mathrm{v} / \mathrm{v} / \mathrm{v} / \mathrm{v}$ ) solvent mixture and $10 \%$ methanolic Sulphuric Acid Reagent was used as spray reagent for separation of flavanoids. Tannins were separated on chromatogram by using the solvent system comprising of mid-polar to non-polar solvents, hence Toluene: Ethyl Acetate: Formic Acid (6:4:0.3 v/v/v) as solvent system and alcoholic $\mathrm{FeCl}_{3}$ was used for derivatization. Results: Distinct fingerprint of flavanoids and tannins was obtained. A profile of 11 to 12 polyvalent phytoconstituents were separated during the HPTLC analysis of flavonoids and tannins respectively. Conclusion: The HPTLC analysis successfully demonstrated that phenolic secondary metabolites can be effectively separated using the same extract under different development conditions. The detection and profiling of such metabolites provides the justification for therapeutic activities in medicinal plants.

Key words: HPTLC, Flavonoids, Tannins, Abrus precatorius L., Sapindus trifoliatus L., Embelia ribes Burm. F.
\end{abstract}

\section{INTRODUCTION}

Phenolic compounds encompassing a wide range of phytochemicals consisting of an aromatic ring with one or more hydroxyl groups. These compounds are mainly synthesized via the shikimate pathway but the polyketide pathway is also responsible for the biosynthesis of some phenolics. ${ }^{1}$ Flavanoids forms the largest group among the phenolics and are characterized by the presence of two benzene rings which are joined by a propane unit. Tannins are polymers of polyphenols that are classified into two types, i.e., hydrolyzable and condensed tannins. HPTLC is widely used in the evaluation of diversity of various class of secondary metabolites from the same plant extract as well as for the development of characteristic chemical fingerprint of the entire plant extract. ${ }^{2,3}$ Literature review suggests that it is possible to achieve the separation of desired class of secondary metabolites from the same extract by choosing appropriate solvent system during the HPTLC analysis. ${ }^{46}$ The present investigation were carried out by selecting appropriate solvent system for screening of flavonoids and tannins from medicinal plants Abrus precatorius L., Sapindus trifoliatus L. and Embelia ribes Burm. F. These plants are reported to exhibit antifertility activity and are quite common in Western Ghats region of Maharashtra. ${ }^{7}$
Submission Date: 18-04-2020; Revision Date: 17-07-2020; Accepted Date: 23-10-2020

DOI: 10.5530/ijper.54.4.205 Correspondence:

Dr. Amit Yadaorao Saraf Government of Maharashtra's Ismail Yusuf College, Jogeshwari (E), Mumbai, Maharashtra INDIA.

Phone: +91 9867942898 E-mail: aysaraf@gmail.com

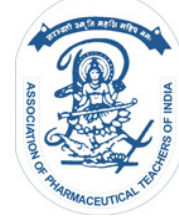

www.ijper.org 


\section{MATERIALS AND METHODS}

\section{Preparation of extracts}

$1 \%$ methanolic extract of air dried pericarp of Sapindus trifoliatus L., berries of Embelia ribes Burm. F. and seeds of Abrus precatorius L. was Sonicated for $15 \mathrm{~min}$ in a bath sonicator without interval.

\section{HPTLC fingerprinting}

The HPTLC analyses was performed on aluminium plates pre-coated with silica gel $60 \mathrm{~F}_{254}$, Merk, Germany. $1 \mu \mathrm{L}, 2 \mu \mathrm{L}$ and $5 \mu \mathrm{L}$ of extract was applied on the plate of $20 \times 10 \mathrm{~cm}$ as bands of $8 \mathrm{~mm}$ width with the help of CAMAG Linomat V sample applicator. The plates were developed in a CAMAG Automatic Development Chamber 2 (ADC2) which was previously equilibrated with a mobile phase for $20 \mathrm{~min}$. Flavonoids were separated using the solvent system of ethyl acetate: formic acid: galcial acetic acid: water (10:0.5:0.5:1 $\mathrm{v} / \mathrm{v} / \mathrm{v} / \mathrm{v}) .10 \%$ methanolic Sulphuric Acid Reagent was used as spray reagent. Tannins were separated on chromatogram by using Toluene: Ethyl Acetate: Formic Acid (6:4:0.3 v/v/v) as solvent system and alcoholic $\mathrm{FeCl}_{3}$ was used for derivatization (Wagner, Eike Reich). The plate was developed up to $8 \mathrm{~cm}$, air dried, viewed and scanned at wavelength of 254 and $366 \mathrm{~nm}$ using CAMAG TLC Scanner 4 and CAMAG Visualizer 2. The plate was then derivatized in Automated CAMAG Derivatizer at level 3. The plate was heated at $105^{\circ} \mathrm{C}$ on CAMAG Plate heater till the development of colour. Derivatized chromatogram was again scanned at 254, 366 and $540 \mathrm{~nm}$ using CAMAG vision CATS software. ${ }^{6}$

\section{RESULT AND DISCUSSION}

The extracts of Abrus precatorius L., Sapindus trifoliatus L. and Embelia ribes Burm. F. Were subjected to generate HPTLC finger printing profile represented as chromatogram. The solvent system used in the investigation was found to give compact spots for extracts at different $\mathrm{R}_{f}$ values and there was no overlap with any other component in the analysed sample. The spots were best observed at $366 \mathrm{~nm}$ after derivatization (Figure 1 and 2: HPTLC profile of Flavonoids in $1 \mu \mathrm{L}$, $2 \mu \mathrm{L}$ and $5 \mu \mathrm{L}$ extracts of $A$. precatorius, $S$. trifoliatus and $E$. ribes at $366 \mathrm{~nm}$ and $254 \mathrm{~nm}$ after derivatization; Figure 3 and 4: HPTLC profile of Tannins in $1 \mu \mathrm{L}, 2 \mu \mathrm{L}$ and $5 \mu \mathrm{L}$ extracts of $A$. precatorius, $S$. trifoliatus and E. ribes at 366 $\mathrm{nm}$ and $540 \mathrm{~nm}$ after derivatization.).

The results from HPTLC finger print scanned at wavelength $366 \mathrm{~nm} 2 \mu \mathrm{L}$ extract of $A$. precatorius for flavonoids (Figure 5 Densitogram and corresponding $\mathrm{R}_{f}$ values of $2 \mu \mathrm{L}$ extract of $A$. precatorius for

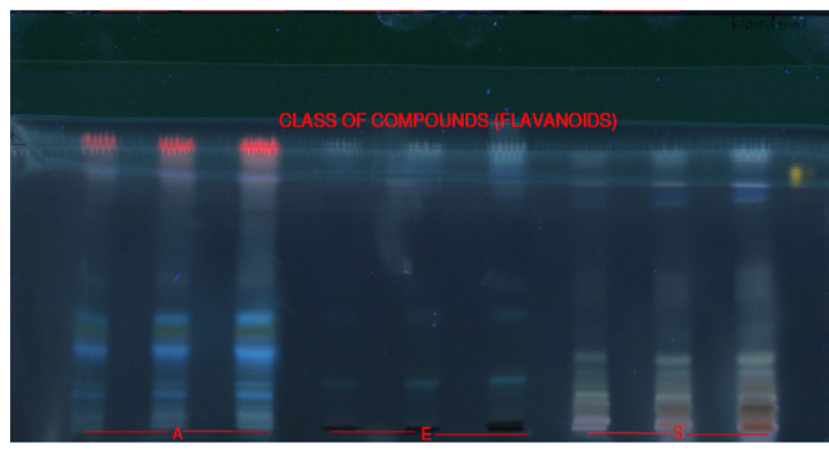

Figure 1: HPTLC profile of Flavonoids in $1 \mu \mathrm{L}, 2 \mu \mathrm{L}$ and $5 \mu \mathrm{L}$ extracts of $A$. precatorius, S. trifoliatus and $E$. ribes at $366 \mathrm{~nm}$ after derivatization.

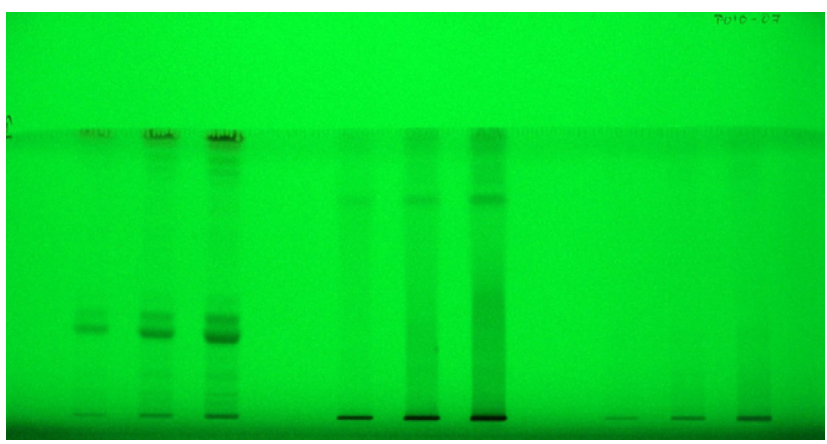

Figure 2: HPTLC profile of Flavonoids in $1 \mu \mathrm{L}, 2 \mu \mathrm{L}$ and $5 \mu \mathrm{L}$ extracts of $A$. precatorius, S. trifoliatus and $E$. ribes at $254 \mathrm{~nm}$ after derivatization.

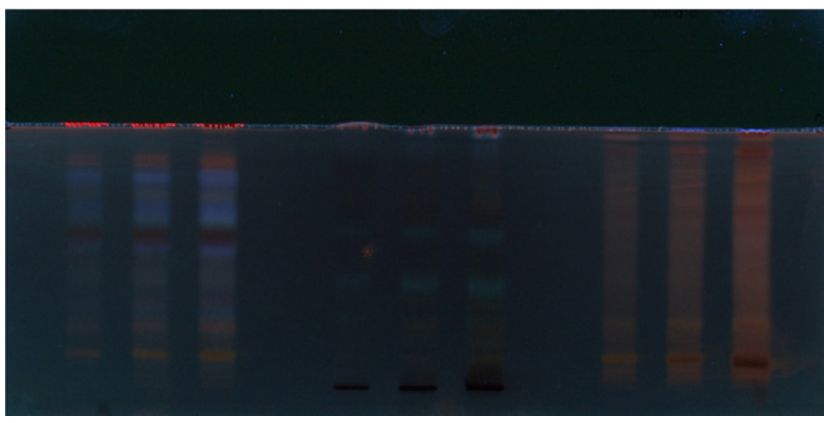

Figure 3: HPTLC profile of Tannins in $1 \mu \mathrm{L}, 2 \mu \mathrm{L}$ and $5 \mu \mathrm{L}$ extracts of $A$. precatorius, $S$. trifoliatus and $E$. ribes at $366 \mathrm{~nm}$ after derivatization.

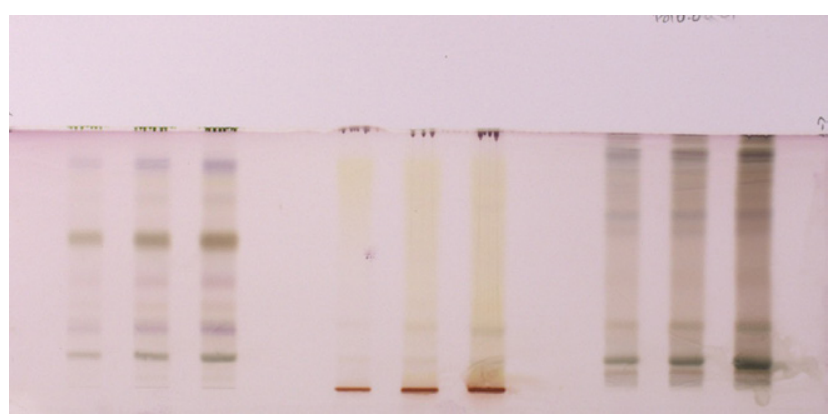

Figure 4: HPTLC profile of Tannins in $1 \mu \mathrm{L}, 2 \mu \mathrm{L}$ and $5 \mu \mathrm{L}$ extracts of $A$. precatorius, $S$. trifoliatus and $E$. ribes at $540 \mathrm{~nm}$ after derivatization. 
flavonoids) reveal the occurrence of 11 polyvalent phytoconstituents with corresponding $\mathrm{R}_{f}$ values of $0.04,0.12,0.15,0.26,0.38,0.53,0.57,0.74,0.80,0.89$ and 1.00. As shown in Figure 1 out of 11 components, the component with $\mathrm{R}_{f}$ values $0.26,0.38,0.89$ and 1.00 were found to be more predominant as the percentage area was more with $10.23 \%, 5.47 \%, 14.43 \%$ and $54.61 \%$ respectively. Among these the highest concentration of the phytoconstituents was found to be $54.61 \%$ and its corresponding $\mathrm{R}_{f}$ value was found to be 1.00 . The remaining components were found to be very less in quantity as the percent area for all the spots were less than $5.0 \%$.

The results from HPTLC finger print scanned at wavelength $366 \mathrm{~nm}$ for $2 \mu \mathrm{L}$ E. ribes (Figure 6). Densitogram and corresponding $\mathrm{R}_{f}$ values of $2 \mu \mathrm{L}$ extract of E. ribes for flavonoids) reveal the occurrence of 8 polyvalent phytoconstituents and corresponding ascending order of $\mathrm{R}_{f}$ values is $0.02,0.16,0.39,0.50$, 0.77, 0.87, 0.91 and 0.97. As shown in Figure 6, 6 out of 8 components, the component with $\mathrm{R}_{f}$ values 0.02 , $0.16,0.39,0.50,0.87,0.91$ and 0.97 were found to be more predominant as the percentage area was more with $10.41 \%, 19.21 \%, 6.34 \%, 8.33 \%, 11.62 \%, 9.59 \%$ and $33.72 \%$ respectively. Among these the highest concentration of the phytoconstituents was found to be $33.72 \%$ and its corresponding $\mathrm{R}_{f}$ value was found to be 0.97. The remaining components was found to be very less in quantity as the percent area for the spot was less than $5.0 \%$.

The results from HPTLC finger print scanned at wavelength $366 \mathrm{~nm}$ for $5 \mu \mathrm{L} S$. trifoliatus (Figure 7 Densitogram and corresponding $\mathrm{R}_{f}$ values of $5 \mu \mathrm{L}$ extract of $S$. trifoliatus for flavanoids) reveal the occurrence of 11 polyvalent phytoconstituents and corresponding ascending order of $\mathrm{R}_{f}$ values is $0.01,0.10,0.18,0.22$, $0.30,0.47,0.53,0.64,0.80,0.85$ and 0.96 . As shown in Figure 7, 3 out of 11 components, the component with $\mathrm{R}_{f}$ values $0.10,0.18,0.22,0.28,0.80,0.85$ and 0.96 were found to be more predominant as the percentage area was more with $9.83 \%, 12.12 \%, 14.37 \%, 5.4 \%$, $8.15 \%, 8.27 \%$ and $28.40 \%$ respectively. Between these the highest concentration of the phytoconstituents was found to be $22.75 \%$ and its corresponding $\mathrm{R}_{f}$ value was found to be 0.96 . The remaining components were found to be very less in quantity as the percent area for all the spots were less than $5.0 \%$.

Flavonoids comprise a large group of plant secondary metabolites characterized by a Diphenyl propane structure (C6-C3-C6). They are widely distributed throughout the plant kingdom and are commonly found in fruits, vegetables and certain beverages. Numerous preclinical

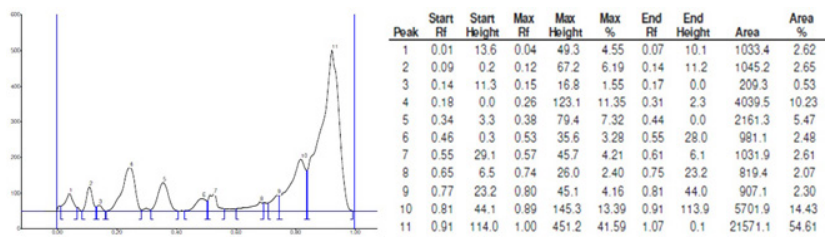

Figure 5: Densitogram and corresponding $\mathbf{R}_{f}$ values of $2 \mu \mathrm{L}$ extract of $\boldsymbol{A}$. precatorius for flavanoids.

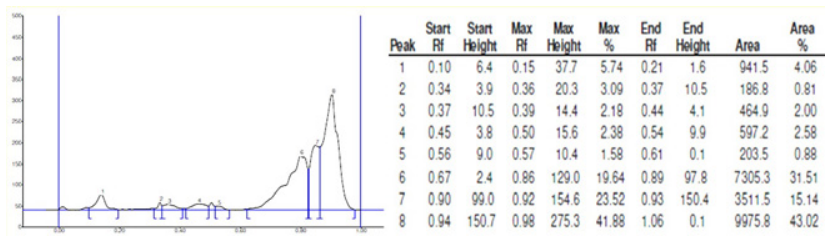

Figure 6: Densitogram and corresponding $R_{f}$ values of $2 \mu \mathrm{L}$ extract of $E$. ribes for flavanoids.

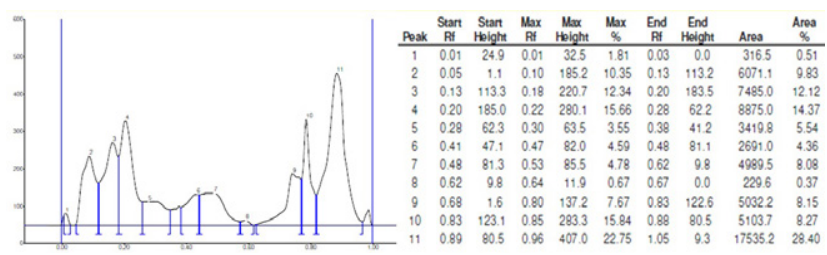

Figure 7: Densitogram and corresponding Rf values of $5 \mu \mathrm{L}$ extract of $S$. trifoliatus for flavanoids.

and some clinical studies suggest that flavonoids have potential for the prevention and treatment of several diseases like free radical scavenging and enzyme inhibitory activities, antioxidant effects, antibacterial effect, anti-cancer effect, cardio protective effects, immune system promoting and anti-inflammatory effects, skin protective effect from UV radiation, Alzheimer's and Parkinson's diseases ${ }^{8-11}$

The results from HPTLC finger print of Tannins scanned at $540 \mathrm{~nm}$ wavelength for $5 \mu \mathrm{L}$ extract of A. Pretorius (Figure 8. Densitogram and corresponding $\mathrm{R}_{f}$ values of $5 \mu \mathrm{L}$ extract of $A$. precatorius for Tannins) reveal the occurrence of 10 polyvalent phytoconstituents with corresponding $\mathrm{R} f$ values of $0.01,0.05,0.13,0.24$, $0.32,0.42,0.57,0.74,0.86$ and 0.99 . As shown in Figure 8,6 out of 10 components, the component with $\mathrm{R}_{f}$ values $0.13,0.24,0.32,0.42,0.57$ and 0.86 were found to be more predominant as the percentage area was more with $16.30 \%, 19.19 \%, 5.29 \%, 11.66 \%, 31.96 \%$ and $10.38 \%$ respectively. Among these the highest concentration of the phytoconstituents was found to be $31.96 \%$ and its corresponding $\mathrm{R}_{f}$ value was found to be 0.57 . The remaining components were found to be very less in quantity as the percent area for all the spots were less than $5.0 \%$. The results from HPTLC finger 


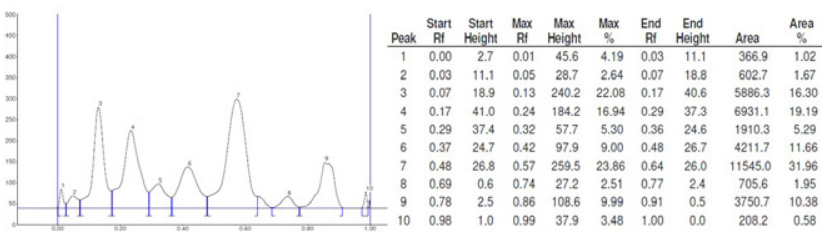

Figure 8: Densitogram and corresponding $R_{f}$ values of $5 \mu \mathrm{L}$ extract of $\boldsymbol{A}$. precatorius for Tannins.

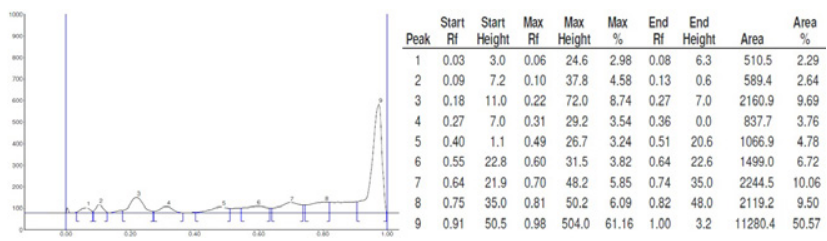

Figure 9: Densitogram and corresponding $R_{f}$ values of $5 \mu \mathrm{L}$ extract of $E$. ribes for Tannins.

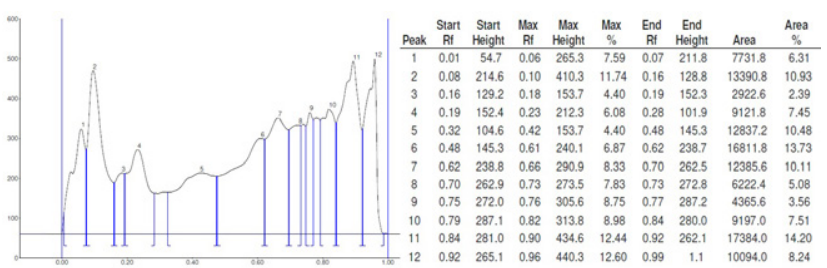

Figure 10: Densitogram and corresponding $R_{f}$ values of $2 \mu \mathrm{L}$ extract of $S$. trifoliatus for Tannins.

print for Tannins scanned at $540 \mathrm{~nm}$ wavelength for $5 \mu \mathrm{L}$ E. ribes (Figure 9. Densitogram and corresponding $\mathrm{R}_{f}$ values of $5 \mu \mathrm{L}$ extract of E. ribes for Tannins) reveal the occurrence of 9 polyvalent phytoconstituents and corresponding ascending order of $\mathrm{R}_{f}$ values is 0.06 , $0.10,0.22,0.31,0.49,0.60,0.70,0.81$ and 0.98 . As shown in Figure 95 out of 9 components, the component with $\mathrm{R}_{f}$ values $0.22,0.60,0.70,0.81$ and 0.98 were found to be more predominant as the percentage area was more with $10.41 \%, 19.21 \%, 6.34 \%, 8.33 \%, 11.62 \%$, $9.59 \%$ and $33.72 \%$ respectively. Among these the highest concentration of the phytoconstituents was found to be $0.57 \%$ and its corresponding $\mathrm{R}_{f}$ value was found to be 0.98 . The remaining components were found to be very less in quantity as the percent area for the spot was less than $5.0 \%$.

The results from HPTLC finger print for Tannins scanned at $540 \mathrm{~nm}$ wave length for $2 \mu \mathrm{L} S$. Trifoliatus (Figure 10 Densitogram and corresponding $\mathrm{R}_{f}$ values of $2 \mu \mathrm{L}$ extract of $S$. trifoliatus for Tannins) reveal the occurrence of 12 polyvalent phytoconstituents and corresponding ascending order of $\mathrm{R}_{f}$ values is 0.06 , $0.10,0.18,0.23,0.42,0.61,0.66,0.73,0.76,0.82,0.90$ and 0.96. As shown in Figure 10, 10 out of 12 components, the component with $\mathrm{R}_{f}$ values $0.06,0.10,0.23,0.42$,
$0.61,0.66,0.73,0.82,0.90$ and 0.96 were found to be more predominant as the percentage area was more with $6.31 \%, 10.93 \%, 7.45 \%, 10.11 \%, 5.08 \%, 7.51 \%$, $14.20 \%$ and $8.25 \%$ respectively. Between these the highest concentration of the phytoconstituents was found to be $14.20 \%$ and its corresponding $\mathrm{R}_{f}$ value was found to be 0.90. The remaining components were found to be very less in quantity as the percent area for all the spots were less than $5.0 \%$.

Tannins belong to polyphenolic compounds and available in various plant parts like leaves, roots, Stem bark, flower and fruits and largely distributed in various species of higher plants. Tannins play various roles in higher plants such as provide protection against predation, act as pesticides, antioxidant, free radical scavenging activity, anti-microbial, anti-cancer, anti-nutritional anti-bacterial and anti-fungal activity. It also shows cardio-protective, hepatoprotective and hpoglycemicproperties ${ }^{12-14}$

\section{CONCLUSION}

Herbal drugs are a complex mixture of active metabolites. Bioactivity of herbals is not entirely due to the presence of any single active principle but is dedicated to the presence of a wide array of complex metabolites often working synergistically. HPTLC allows the profiling of various classes of secondary metabolites from the same or different plants by choosing the solvent system of varying polarity. Multiple fingerprints from different plant sources can be simultaneously developed, each representing the profile of the same class of compound. The present study demonstrates the utility of HPTLC for studying each class of phenolic compounds from three different sources on the same plate. Diversity in flavonoids and tannins can be further worked upon to evaluate the bioactivity of individual phenolic compounds for their pharmaceutical application.

\section{ACKNOWLEDGEMENT}

Authors thank ANCHROM Enterprises, Mumbai for providing the facility for HPTLC analysis.

\section{CONFLICT OF INTEREST}

Authors hereby declare that there is no conflict of interest

\section{ABBREVIATIONS}

HPTLC: High Performance Thin Layer Chromatography; $\mu \mathrm{L}$ : Micro litre; $\mathbf{n m : ~ N a n o ~ m e t e r ; ~} \mathbf{R}_{\boldsymbol{f}}$ Retardation factor; v/v: Volume by volume. 


\section{REFERENCES}

1. Osbourn AE, Lanzotti V. Plant-derived natural products. Dordrecht: Springer. 2009.

2. Aparna S, Aruna S. HPTLC fingerprint profile of steroidal constituents of Achyranthes aspera Linn. Journal of Biomedical and Pharmaceutical Research. 2014;3(5):60-6.

3. Saraf A, Saraf A, Chaturvedi A. Phytochemical analysis and chemical fingerprinting of seeds of Abrus precatorius L. Chem Sci Trans. 2018;7(1):63-70. DOI:10.7598/cst2018.1460

4. Saraf A. Phytochemical and Antimicrobial Studies of Medicinal Plant Piper longum Linn. International Journal of Pharmacognosy and Phytochemical Research. 2014;6(2):213-22.

5. Wagner $\mathrm{H}$, Bladt S. Plant drug analysis: A thin layer chromatography atlas. Springer Science and Business Media. 1996.

6. Reich E, Schibli A. High-performance thin-layer chromatography for the analysis of medicinal plants. Thieme. 2007.

7. Poharkar RD, Saraswat RK, Kotkar S. Survey of plants having antifertility activity from western ghat area of Maharashtra state. J Herb Med Toxicol. 2010;4(2):71-5.

8. Dirar Al, Alsaadi DH, Wada M, Mohamed MA, Watanabe T, et al. Effects of extraction solvents on total phenolic and flavonoid contents and biological activities of extracts from Sudanese medicinal plants. South African Journal of Botany. 2019;120:261-7. doi.org/10.1016/j.sajb.2018.07.003

9. Tungmunnithum D, Thongboonyou A, Pholboon A, Yangsabai A. Flavonoids and other phenolic compounds from medicinal plants for pharmaceutical and medical aspects: An overview. Medicines. 2018;5(3):93. doi.org/10.3390/ medicines5030093

10. Teles RB, Diniz TC, Pinto TC, DeOliveira JRG, Silva MG, Lavor EM, et al. Flavonoids as therapeutic agents in Alzheimer's and Parkinson's diseases: a systematic review of preclinical evidences. Oxid Med Cell Longev. 2018;21. doi.org/10.1155/2018/7043213

11. Sureshkumar R. Flavonoids as Adjuvant in Psoralen-based Phytochemotherapy in the Management of Vitiligo/Leukoderma. Asian Journal of Pharmaceutics (AJP): Free full Text Articles from Asian J Pharm. 2019;13(02).doi.org/10.22377/ajp.v13i02.3103

12. Carvalho RS, Carollo CA, DeMagalhães JC, Palumbo JM, Boaretto AG, eSá IN, et al. Antibacterial and antifungal activities of phenolic compoundenriched ethyl acetate fraction from Cochlospermum regium (mart. Et. Schr.) Pilger roots: Mechanisms of action and synergism with tannin and gallic acid. South African Journal of Botany. 2018;114:181-7. doi.org/10.1016/j. sajb.2017.11.010

13. Smeriglio A, Barreca D, Bellocco E, Trombetta D. Proanthocyanidins and hydrolysable tannins: occurrence, dietary intake and pharmacological effects. British Journal of Pharmacology. 2017;174(11):1244-62. doi.org/10.1111/ bph. 13630

14. Sobeh M, Mahmoud MF, Abdelfattah MA, El-Beshbishy HA, El-Shazly AM, Wink M. Hepatoprotective and hypoglycemic effects of a tannin rich extract from Ximenia americana var. caffra root. Phytomedicine. 2017;33:36-42. doi. org/10.1016/j.phymed.2017.07.003.

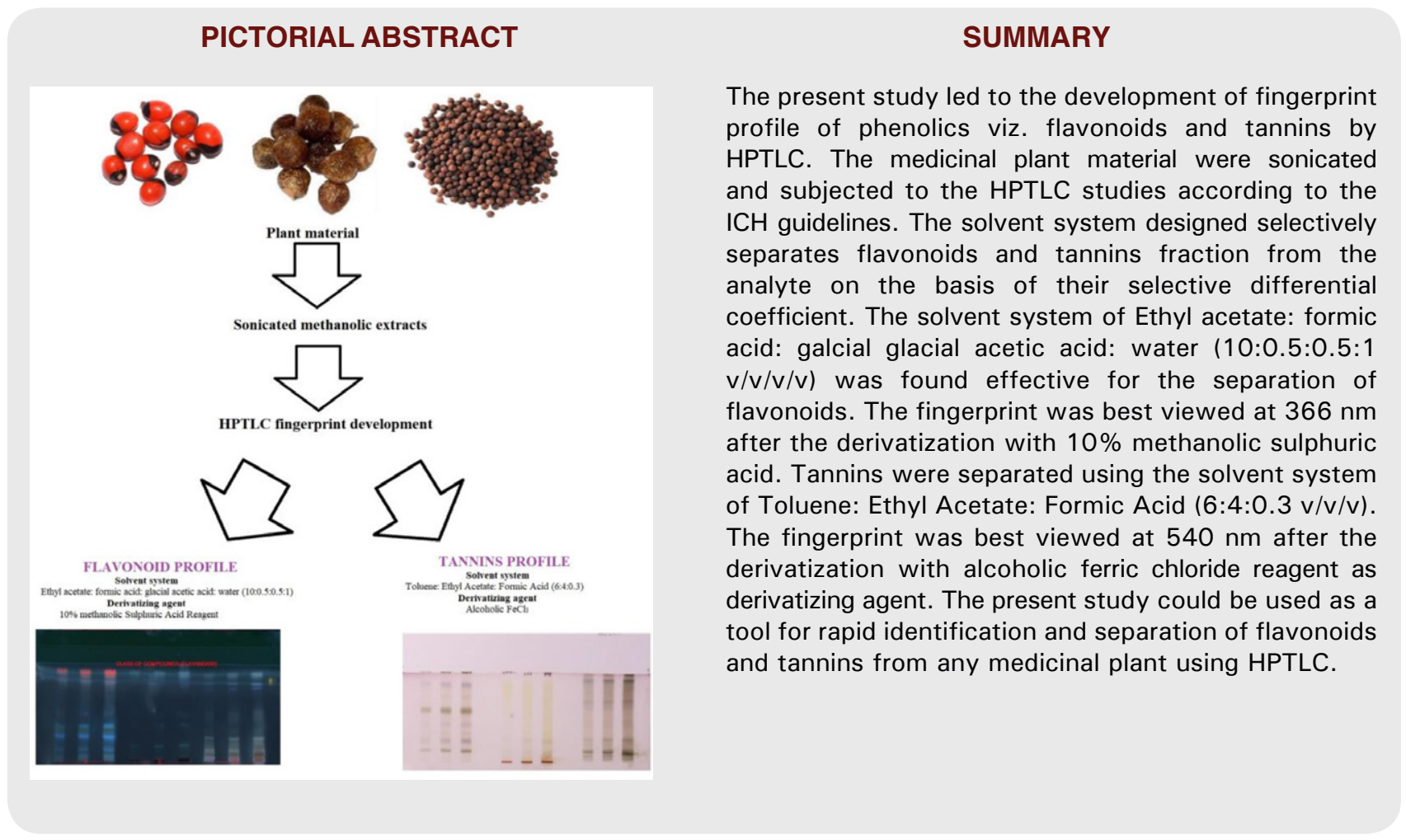




\section{About Authors}

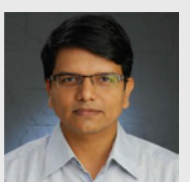

Dr. Amit Yadaorao Saraf, Head, Department of Botany and Biotechnology, Government of Maharashtra, Ismail Yusuf College, Mumbai, has teaching experience of more than 20 years. He has cleared NET \& SET examination and is currently working on a project involving HPTLC evaluation of steroids \& flavanoids in medicinal plants.

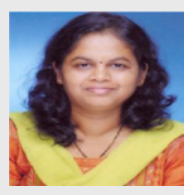

Dr. Aparna Amit Saraf is working as an Associate Professor at The Institute of Science, Mumbai, Dr Homi Bhabha State University, for last 24 yrs at PG level. She is Member, Academic Council, HBSU and Member, BoS (University of Mumbai and SNDT University). She is also working on various State and National level bodies in various capacities. She has 5 Ph.D students and 41 Research papers to her credit.

Cite this article: Saraf AY, Saraf AA. HPTLC Fingerprinting: A Tool for Simplified Analysis of Phenolics in Medicinal Plants. Indian J of Pharmaceutical Education and Research. 2020;54(4):1098-103. 